\title{
An infant with chronic hypernatremia
}

\author{
M L Marcovecchio \\ Department of Paediatrics, University of Chieti, Via dei Vestini 5, 66100 Chieti, Italy \\ (Correspondence should be addressed to M L Marcovecchio; Email: Imarcovecchio@yahoo.it)
}

\begin{abstract}
A 4-month-old boy was presented with failure to thrive, refusal to feed, delayed motor development, truncal hypotonia, and head lag. His plasma osmolality and sodium were significantly high, while his urine osmolality was inappropriately low and did not increase after desmopressin administration. Despite his hyperosmolality, he presented with a lack of thirst and became clearly polyuric and polydipsic only at the age of 2 years. Initial treatment with indomethacin was ineffective, while the combination of hydrochlorothiazide and amiloride was effective and well tolerated.
\end{abstract}

European Journal of Endocrinology 155 S141-S144

\section{Introduction}

Chronic hypernatremia in young patients is generally the result of alterations in the mechanisms controlling fluid balance (1). Excessive water loss, as in diabetes insipidus, or an inadequate fluid intake, as in adipsic hypernatremia, may be the underlying cause. The differential diagnosis between these conditions is important in order to choose the appropriate treatment. However, pitfalls in the diagnosis are often related to an unusual presentation, particularly in infants.

\section{Case report}

A boy (presently 3.5 years) was admitted at the age of 4 months with a history of failure to thrive, delayed motor milestones, refusal to feed, and lack of thirst. He was born after an uneventful pregnancy and delivered at 40 weeks. His weight at birth was $2.3 \mathrm{~kg}$ ( $<-2$ SDS). He was the first child of healthy, unrelated parents.

Weight and length were both below the third percentiles. He had central hypotonia and a marked head lag; the rest of the neurological examination was normal.

Investigations showed hypernatremia $(165 \mathrm{mmol} / \mathrm{l})$ and hyperosmolality ( $365 \mathrm{mosmol} / \mathrm{kg}$ ) associated with an inappropriately low urine osmolality $(251 \mathrm{mosmol} / \mathrm{kg}$ ) and sodium excretion $(22 \mathrm{mmol} / \mathrm{l})$. Plasma creatinine and urea were 0.6 and $21.6 \mathrm{mg} / \mathrm{dl}$ respectively. Twentyfour hour fluid intake and output were 680 and $336 \mathrm{ml}$

This paper was presented at the 4th Ferring Pharmaceuticals International Paediatric Endocrinology Symposium, Paris (2006). Ferring Pharmaceuticals has supported the publication of these proceedings.
$(61 \mathrm{ml} / \mathrm{kg})$ respectively. Other investigations including thyroid and adrenal function were normal. He was refusing oral fluids despite being hypernatremic.

A cranial magnetic resonance imaging scan excluded structural abnormalities in the hypophysis, hypothalamus and surrounding area. There was no response to $0.3 \mu \mathrm{g}$ 1-desamino-8-D-arginine-vasopressin (DDAVP) given intravenously (osmolality pre- $374 \mathrm{mosmol} / \mathrm{kg}$; post- $371 \mathrm{mosmol} / \mathrm{kg}$ ). This suggested a tubular defect causing nephrogenic diabetes insipidus (NDI). Plasma vasopressin was $12 \mathrm{pg} / \mathrm{ml}$ (normal range: $2-5 \mathrm{pg} / \mathrm{ml}$ ). A mutation screen of the vasopressin receptor gene 2 (AVPR2) was normal. Treatment was started with indomethacin, $3 \mathrm{mg}$ tds $(1.5 \mathrm{mg} / \mathrm{kg}$ per day $)$ together with a high-caloric intake and increased oral fluids. However, there was no improvement in terms of growth and muscle tone and plasma sodium remained high $(170 \mathrm{mmol} / \mathrm{l})$. Indomethacin was discontinued after 10 months and a gastrostomy was performed to continue management solely by increased fluid and caloric intake.

He started to develop a sense of thirst by 2 years of age, which was followed by evidence of polyuria. His plasma sodium and osmolality remained high: $170 \mathrm{mmol} / \mathrm{l}$ and $340 \mathrm{mosmol} / \mathrm{kg}$ respectively. Treatment was started with hydrochlorothiazide $(3 \mathrm{mg} / \mathrm{kg}$ per day) and amiloride $(0.3 \mathrm{mg} / \mathrm{kg}$ per day; Fig. 1$)$. There was a significant improvement in plasma sodium (144 mmol/l), plasma osmolality (295 mosmol/ $\mathrm{kg}$ ), and a lessening of his polydipsia and polyuria. Muscle tone improved and there was gain in weight. When last reviewed at 3.5 years, weight, height and motor development were continuing to improve and his plasma sodium and osmolality were $140 \mathrm{mmol} / \mathrm{l}$ and $285 \mathrm{mosmol} / \mathrm{kg}$ respectively. 

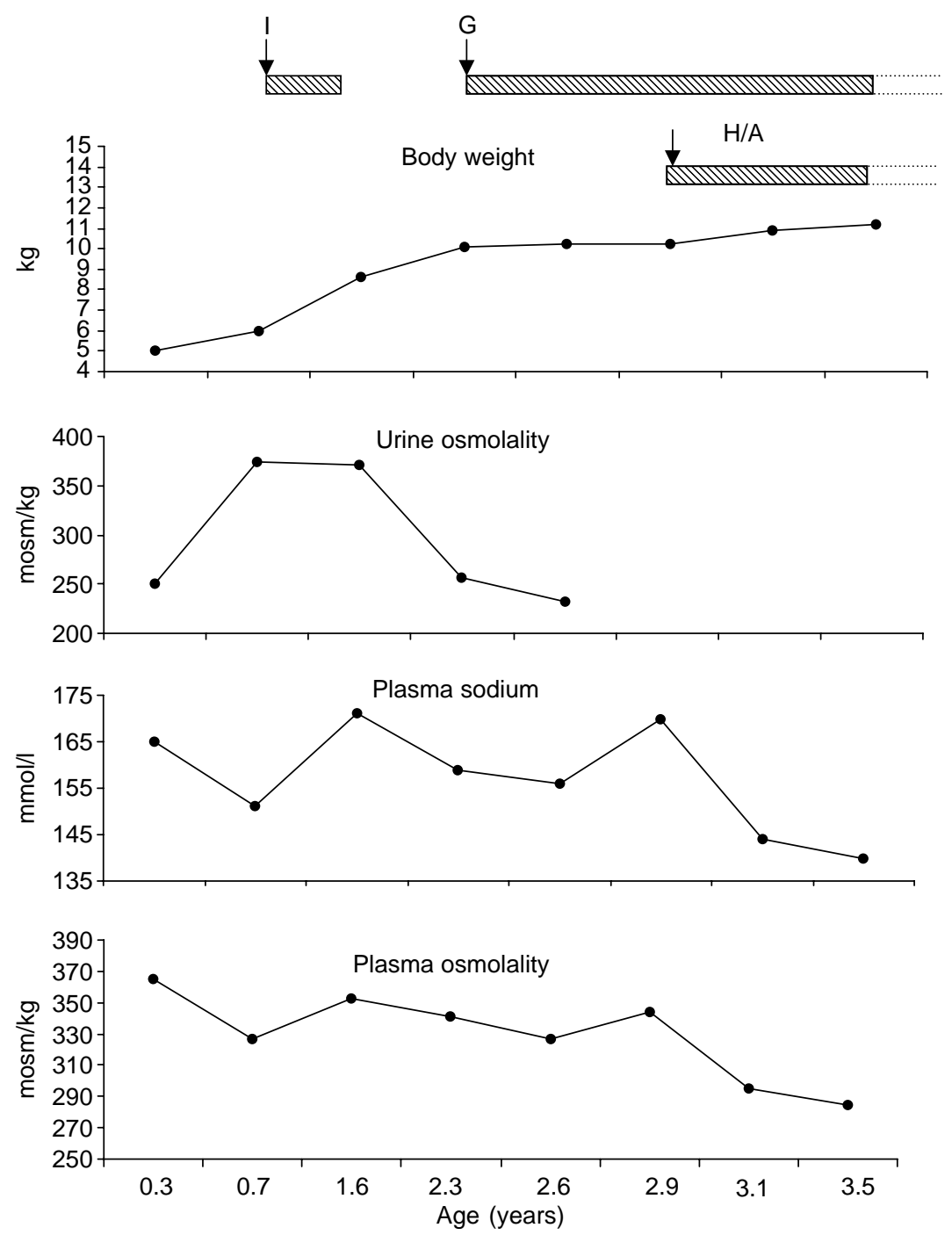

Figure 1 Serial sodium, osmolality and body weight values in relation to treatment in an infant with cNDI. I, indomethacin; G, gastrostomy; $\mathrm{H} / \mathrm{A}$, hydrochlorothiazide and amiloride.

\section{Discussion}

Chronic hypernatremia is generally the result of three mechanisms: excessive sodium intake (salt administration), excess water loss (central and nephrogenic diabetes insipidus), and decreased free water intake (adipsic hypernatremia and physical obstacles to drinking) $(1,2)$.

The differential diagnosis in this case was essentially between diabetes insipidus and adipsic hypernatremia.

Adipsic hypernatremia, also known as essential hypernatremia, is an uncommon disorder of the hypothalamus, characterized by chronic hyperosmolality in the presence of an inappropriate lack of thirst. It is due to a defect in osmoreceptors in the anterior hypothalamus involved in the regulation of thirst (3-5). There may also be an impairment of vasopressin secretion, but there is generally a normal response to exogenous vasopressin and an ability to concentrate urine with fluid restriction $(3,4)$. This infant had absence of thirst associated with hypernatremia, features in favor of a diagnosis of adipsic hypernatremia.

Central diabetes insipidus, defined as an abnormality of urine concentrating ability due to deficient secretion of vasopressin $(6,7)$, was excluded based on random high levels of vasopressin and no urine osmolality response to DDAVP. These findings suggested NDI, even though this infant was not initially polydipsic and polyuric. Absence of polyuria was probably related to a state of dehydration with reduced glomerular filtration. Furthermore, polydipsia and polyuria are often not manifest in infants with NDI and the clinical picture is dominated by more non-specific symptoms and signs, such as vomiting, anorexia, failure to thrive, fever, constipation, and development delay (8). A study of 30 
infants with congenital NDI (cNDI) reported the most common symptoms and signs at first referral in order of frequency were: vomiting or anorexia, failure to thrive, fever and constipation, and less commonly, polydipsia (9). A further review of cNDI cases also reported fever, failure to thrive, and later, short stature; while polyuria and polydipsia were not universal symptoms (10).

NDI may be a congenital, related to genetic abnormalities, or an acquired disorder (Table 1). cNDI is a rare inherited disorder due to an inability of the kidney to concentrate urine in response to vasopressin (11). Clinical manifestations of cNDI generally appear within the first weeks of life. The great majority $(90 \%)$ are due to mutations in the vasopressin receptor gene, which is on chromosome Xq28 and thus affects males; presently 183 different mutations have been identified. About $10 \%$ of cases are due to mutations in the aquaporin 2 (AQP2) gene, the majority being inherited in an autosomal recessive manner. A few autosomal dominant cases are reported $(11,12)$. Analysis of AVPR 2 was normal in the present case and the result of sequencing AQP2 is pending. While mutations in $A V P R 2$ and AQP2 are the most common, other genes have been suggested as responsible for NDI, such as $A Q P 1,3$ as well as genes encoding for factors involved in maintaining interstitial hypertonicity in the renal medulla, including chloride channels, aldose reductase, and urea transporters (12). Presently, there are only experimental data available to implicate their potential role, other than a human case of an AQP1 mutation, which caused a mild phenotype with absent polyuria but an inability to concentrate urine maximally (13).

A particular feature of the present case was central hypotonia and a marked head lag, which improved after treatment. These have been reported previously as the main presenting features in another two cases of NDI (14). Our case required feeding via a gastrostomy to maintain an adequate nutritional and fluid intake to correct his hypernatremia. This is not uncommon in infants with cNDI. The management of NDI is summarized in Table 2.

Hydrochlorothiazide and amiloride treatments were effective in eventually normalizing the plasma sodium without any side effects. Initial treatment with indomethacin had been ineffective. The combination of hydrochlorothiazide and amiloride is well tolerated and

Table 1 Classification of causes of nephrogenic diabetes insipidus.

\begin{tabular}{|c|c|}
\hline \multicolumn{2}{|l|}{ Genetic } \\
\hline X-linked recessive & Vasopressin V2 receptor gene \\
\hline Autosomal recessive & Aquaporin-2 gene \\
\hline Autosomal dominant & Aquaporin-2 gene \\
\hline \multicolumn{2}{|l|}{ Acquired } \\
\hline Metabolic & $\begin{array}{l}\text { Hypocalcemia, hypokalemia, } \\
\text { hyperglycemia, protein malnutrition }\end{array}$ \\
\hline Renal & $\begin{array}{l}\text { Chronic renal disease, impaired } \\
\text { medullary function, outflow obstruction }\end{array}$ \\
\hline Drugs & $\begin{array}{l}\text { Lithium, foscarnet, amphotericin B, } \\
\text { demeclocycline }\end{array}$ \\
\hline
\end{tabular}

Table 2 Principles of management of nephrogenic diabetes insipidus.

\author{
Salt restriction ( $<1 \mathrm{mmol} / \mathrm{kg}$ per day) \\ Adequate water intake \\ Indomethacin: $2 \mathrm{mg} / \mathrm{kg}$ per $24 \mathrm{~h}$ \\ Hydrochlorothiazide: $2-4 \mathrm{mg} / \mathrm{kg}$ two or three times daily \\ Amiloride: $0.3 \mathrm{mg} / \mathrm{kg}$ per $24 \mathrm{~h}$ divided three times per day \\ Hydrochlorothiazide plus amiloride \\ Hydrochlorothiazide plus indometacin \\ Synthetic membrane-permeable AVP or AQP2 antagonists
}

$\mathrm{AVP}$, vasopressin; $A Q P 2$, aquaporin 2 gene.

shown to be generally better than hydrochlorothiazide only. It is not associated with a risk of hypokalemia. The combination of hydrochlorothiazide and indomethacin is equally effective, but this carries the risk of gastrointestinal, renal and hematopoietic complications associated with indomethacin (15).

In conclusion, this case report illustrates the variable presentation of diabetes insipidus. In infants, polydipsia and polyuria are invariably not the presenting manifestations of the disorder, but other aspects, such as failure to thrive, hypotonia, developmental delay, and absence of thirst may be the dominant features.

\section{Key learning points}

- Polydipsia and polyuria are not always the dominant features at presentation of diabetes insipidus in infancy.

- Failure to thrive, refusal to feed and hypotonia may be the main features associated with NDI.

- Gastrostomy may be required to maintain adequate nutrition and fluid intake in cNDI.

- A combination of hydrochlorothiazide and amiloride treatment is effective in controlling fluid homeostasis without side effects.

\section{Acknowledgements}

The author thanks Prof Paul Czernichow for helpful suggestions in the preparation of the manuscript.

\section{References}

1 Verbalis JG. Disorders of body water homeostasis. Best Practice and Research Clinical Endocrinology and Metabolism 200317 471-503.

2 GreenBaum LA. Hypernatremia. 17th edn, In Nelson Textbook of Pediatrics 2004 pp 196-199.

3 Ball SG \& Baylis PH. Hypothalamic adipsic syndrome: diagnosis and management. Clinical Endocrinology 1997 47 405-409.

4 Halter JB, Goldberg AP, Robertson GL \& Porte D. Selective osmoreceptors dysfunction in the syndrome of chronic hypernatremia. Journal of Clinical Endocrinology and Metabolism $1977 \mathbf{4 4}$ 609-616. 
5 Lopez-Capapè M, Golmayo L, Lorenzo G, Gallengo N \& Barrio R. Hypothalamic adipsic hypernatremia syndrome with normal osmoregulation of vasopressin. European Journal of Pediatrics $2004163580-583$.

6 Baylis PH \& Cheetham T. Diabetes insipidus. Archives of Disease in Childhood 1998 79 84-89.

7 Cheetham T \& Baylis PH. Diabetes insipidus in children. Pathophysiology, diagnosis and management. Paediatric Drugs 20024 785-796.

8 Knoers N \& Monnens LA. Nephrogenic diabetes insipidus: clinical symptoms, pathogenesis, genetics and treatment. Pediatric Nephrology $19926476-482$.

9 Van Lieburg AF, Knoers AM \& Monnens LA. Clinical presentation and follow-up of 30 patients with congenital nephrogenic diabetes insipidus. Journal of the American Society of Nephrology 199910 1958-1964.

10 Mizuno H, Sugiyama Y, Ohro Y, Imamine H, Kobayashi M, Sasaki S, Uchida S \& Togari H. Clinical characteristics of eight patients with congenital nephrogenic diabetes insipidus. Endocrine $20042455-59$.
11 Bichet DG. Nephrogenic diabetes insipidus. Advances in Chronic Kidney Disease 200613 96-104.

12 Sasaki S. Nephrogenic diabetes insipidus: update of genetic and clinical aspects. Nephrology, Dialysis, Transplantation 200419 1351-1353.

13 King LS, Choi M, Fernandez PC, Cartron SP \& Agre P. Defective urinary concentrating ability due to a complete deficiency of aquaporin-1. New England Journal of Medicine 2001345 175-179.

14 Sprenger KJ, Winship WS \& Wittenberg DF. Nephrogenic diabetes insipidus presenting with infantile hypotonia. A report of 2 cases. South African Medical Journal 198670 228-231.

15 Kirchlechner V, Koller DY, Seidl R \& Waldhauser F. Treatment of nephrogenic diabetes insipidus with hydroclorothiazide and amiloride. Archives of Disease in Childhood $1999 \mathbf{8 0} 548-552$.

Received 6 July 2006

Accepted 31 July 2006 